\title{
Exploring Simulation Utilization and Simulation Evaluation Practices and Approaches in Undergraduate Nursing Education
}

\author{
Hilde Zitzelsberger* \\ Faculty of Health Sciences, University of Ontario Institute of Technology \\ 2000 Simcoe Street North, Oshawa, Ontario, L1H 7K4, Canada \\ Sue Coffey \\ Faculty of Health Sciences, University of Ontario Institute of Technology \\ 2000 Simcoe Street North, Oshawa, Ontario, L1H 7K4, Canada \\ Leslie Graham \\ Collaborative Nursing Program, Durham College \\ Faculty of Health Sciences, University of Ontario Institute of Technology \\ 2000 Simcoe Street North, Oshawa, Ontario, L1H 7K4, Canada \\ Efrosini Papaconstantinou \\ Faculty of Health Sciences, University of Ontario Institute of Technology \\ 2000 Simcoe Street North, Oshawa, Ontario, L1H 7K4, Canada \\ Charles Anyinam \\ Sally Horsefall Eaton School of Nursing, George Brown College \\ 200 King Street East, Toronto, Ontario, M5A 3W8, Canada
}

The research was financed by Sigma Theta Tau International No. 10047

\begin{abstract}
Simulation-based learning (SBL) is rapidly becoming one of the most significant teaching-learning-evaluation strategies available in undergraduate nursing education. While there is indication within the literature and anecdotally about the benefits of simulation, abundant and strong evidence that supports the effectiveness of simulation for learning and evaluation in nursing education is slow to emerge and has yet to be fully established. As the use of SBL increases in nursing education, the need to evaluate students appropriately, accurately, and in reliable ways intensifies. Furthermore, as nursing programs increasingly consider SBL as direct clinical replacement in the context of increased student enrolment and dwindling clinical placements, standardized evaluation must play a vital role. Our study investigated simulation utilization and simulation evaluation practices and approaches employed among undergraduate nursing educational programs in Ontario, Canada, using a mixed methods approach. Both quantitative and qualitative data were collected through a confidential online survey. The goal of our study is to establish a "picture" of current trends, practices, and approaches related to simulation that is employed within this entire province. An overview of the study findings and recommendations that have potential to make a substantial contribution to the growing evidence for best practices in the science of simulation will be discussed.
\end{abstract}

Keywords: Simulation; Simulation-based Learning, Evaluation; Undergraduate Nursing Education

\section{Introduction}

Simulation-based learning (SBL) is rapidly becoming one of the most significant teaching-learning-evaluation strategies available in undergraduate nursing education (Aebersold \& Tschannen, 2013; Akhtar-Danesh, Baxter, Valaitis, Stanyon, \& Sproul, 2009). Through the development, application, and evaluation of high quality simulation experiences across a full range of modalities, (including high-fidelity, medium-fidelity, and lowfidelity) learners are able to acquire and demonstrate the required prerequisite knowledge, skills, and abilities necessary for safe and ethical nursing practice (Cant \& Cooper, 2010; Rickets, 2011; Shin, Park, \& Kim, 2015). By approximating clinical practice within nursing education, SBL provides real-time opportunities for students to work through complex patient-care situations, ideally receiving evaluative feedback that promotes increased confidence and competence (Cant \& Cooper, 2010; Norman, 2012; Rickets, 2011).

Increasingly, SBL is playing an essential role in supporting educators to facilitate nursing students' learning of complex concepts and skills (Canadian Association of Schools of Nursing, 2007, 2015; Rickets, 2011). In clinical settings, the shift to higher acuity and increased complexity of patients demands higher levels of decision-making, further necessitating increased confidence and competency among nursing students and program graduates. A number of studies demonstrate the advantages of SBL in enhancing nursing students' knowledge, competence, confidence, and satisfaction, while readying students to practice in complex healthcare 
environments (Cant \& Cooper, 2010; Norman, 2012; Rickets, 2011). While there is indication within the literature and anecdotally about the benefits of simulation, abundant and strong evidence that supports the effectiveness of simulation for learning and evaluation in nursing education is slow to emerge and has yet to be fully established (Alexander et al., 2015; Canadian Association of Schools of Nursing, 2015; Hayden, Smiley, Alexander, Kardong-Edgren, \& Jeffries, 2014; Rickets, 2011).

As the use of SBL increases in nursing education, the need to evaluate students appropriately, accurately, and in reliable ways intensifies in all domains of learning (e.g., psychomotor, cognitive and affective domains) (Andreatta \& Lori, 2014, Bensfield, Oleach, \& Horsley, 2012; Ricketts, 2011; Todd, Manz, Hawkins, Parsons, \& Hercinger, 2008). Furthermore, as nursing programs increasingly consider SBL as direct clinical replacement in the context of increased student enrolment and dwindling clinical placements, standardized evaluation must play a vital role (Canadian Association of Schools of Nursing, 2007; Norman, 2012; Smith, 2007; Todd et al., 2008). Adamson, Kardong-Edgren, \& Willhaus (2013) note that evaluation is a critical, yet often overlooked component of simulation practice and research. Developing comprehensive insight into current nursing educational practices and approaches in relation to the utilization and evaluation of simulation for nursing education is a critically important undertaking, necessary to solidify the foundation for future development of the science of simulation for nursing education.

\section{The Study Purpose and Methods}

\subsection{Purpose and Aims}

The purpose of this study is to investigate simulation utilization and simulation evaluation practices used among undergraduate nursing educational programs in Ontario, Canada. In so doing, this study findings establish a "picture" of current trends, practices, and approaches related to simulation that are employed within this entire province. Specific areas for investigation include:

1. The simulation modalities (high, medium, low fidelity) that are employed in undergraduate nursing education in Ontario, including the degree to which they are utilized across the various nursing educational programs and models in this province;

2. The common simulation foci that are included in undergraduate nursing programs in Ontario; and

3. The current evaluation approaches and practices specifically related to simulation in nursing education, including evaluating students (formative, summative, high stakes, and remedial evaluation), students' evaluation of the simulation for learning, evaluation practices as they are applied to examining the simulation itself, and evaluation of personnel involved in teaching-learning with simulation.

\subsection{Theoretical Orientation}

This study is situated within a perspective that recognizes the significance of best practices in the science of simulation to transform nursing education. Simulation is an emerging field with great potential for supporting active learning and student engagement. As such, there is a recent movement to establish practices that ultimately will promote and ensure patient safety (Alexander et al., 2015; Canadian Association of Schools of Nursing, 2015; Hayden et al., 2014; Rickets, 2011). As the use of SBL in nursing education increases, the need to investigate the use of simulation as a method to evaluate student performance in nursing education is essential. As a quality improvement initiative, there also is a need to assess simulation evaluation practices and approaches.

\subsection{Study Methods}

\subsubsection{Methods}

In this study, a mixed methods approach was utilized, wherein both quantitative and qualitative data collection took place through a confidential online questionnaire. The focus was to ascertain current practices in undergraduate nursing education in Ontario, Canada, specifically in relation to the utilization and evaluation of simulation. This study successfully underwent ethics reviews and approval processes at the authors' home academic institutions and where required, at institutions that were being surveyed.

\subsubsection{Sampling}

To ascertain a comprehensive picture representing the state of the science of simulation in Ontario's undergraduate nursing educational programs, non-random and purposeful sampling was employed. The entry to practice requirement for registered nurses in Ontario is a baccalaureate degree. In this province, a total of 36 educational institutions (14 universities along with 22 college partners) are involved in either independently or collaboratively offering baccalaureate degrees in nursing. This research sought input from all of these 36 educational programs to gain insight into the practices and approaches focusing on inclusion and evaluation of simulation in nursing education across the entire province.

2.3.3 Procedures

A questionnaire comprised of quantitative and qualitative questions was developed to examine current practices and approaches in relation to inclusion and evaluation of simulation in Ontario undergraduate nursing education. 
The survey contained 52 questions, and was delivered to participants in a secure online format that was selfguiding and confidential. The closed-ended questions contained pre-coded responses while open-ended questions allowed participants to individualize their responses and elaborate on the practices around evaluation of all components of simulation for nursing education. Informed consent, as the first screen of the online questionnaire, was obtained through the online questionnaire.

In addition to some basic questions about the type of nursing program offered (standard four year degree, second entry or accelerated, bridging) and enrolment date, the survey focused on three broad categories of inquiry:

1. Overview of simulation inclusion in undergraduate nursing programs in Ontario, including the simulation modality (high, medium, and low fidelity)

2. Specific simulation foci that are included in undergraduate nursing programs in Ontario

3. Comprehensive identification of evaluation approaches and practices in simulation, including:
i. Formative evaluation
ii. Summative evaluation
iii. High stakes evaluation
iv. Remedial evaluation
v. Student evaluations of the simulated learning
vi. Evaluation practices focusing on the simulation itself
vii. Evaluation of personnel involved in teaching-learning with simulation

For the recruitment process, academic leaders at all Ontario nursing programs were invited to either complete the questionnaire themselves or to pass the letter of invitation to key informants (e.g., simulationists, technologists or technicians, faculty, staff, leaders) with specific knowledge about simulation within that given nursing program to complete the questionnaire. Individual informants or a team of informants could choose to complete the survey. Participants were able to access the online questionnaire via a link included in the letter of invitation. Follow-up emailed letters of invitation were sent if a response had not been received to the first letter of invitation.

Analytic procedures involved a detailed examination of the data set pertaining to participant(s) representing an Ontario undergraduate nursing program, followed by a systematic and comparative analysis of the data sets generated from all sites. Quantitative data was analyzed using excel software. Basic descriptive statistics were employed to create a composite picture of simulation inclusion, simulation foci, and common practices and approaches to evaluation specifically focusing on simulation in nursing education in Ontario. Qualitative responses were analyzed as group/aggregate data to identify common themes to answer the research questions.

\section{Study Findings}

\subsection{Simulation Inclusion}

Participants' responses to the questionnaire indicated that SBL is used in both clinical and non-clinical courses. However, simulation experiences are most often integrated into clinical courses. Respondents indicated that clinical courses $(51 \%)$ and lab courses $(51 \%)$ most frequently included simulation and that simulation is occasionally included in nursing theory courses (32\%). Only 3\% of participants responded that simulation is included in non-nursing theory courses and only $3 \%$ responded that simulation is included in interprofessional clinical or theory courses. All responding representatives of colleges and universities (100\%) indicated that all types of fidelity (e.g., low fidelity, medium fidelity, high fidelity) are used in simulation throughout all the years of their program.

In response to whether new simulation hours have been added to their undergraduate nursing program during the $2013-2014$ academic year, over half $(58 \%)$ of responding participants indicated that their programs increased hours of simulation. Increased faculty expertise in SBL approaches, followed by faculty requests and curriculum changes, were reported as the most influential factors prompting increased simulation hours. An additional motivator included student requests. Increased student enrollment, limited placement availability, changes among agencies used for student placements, and limited preceptor availability were ranked as less important motivators in increasing simulation hours (See figure 1). 


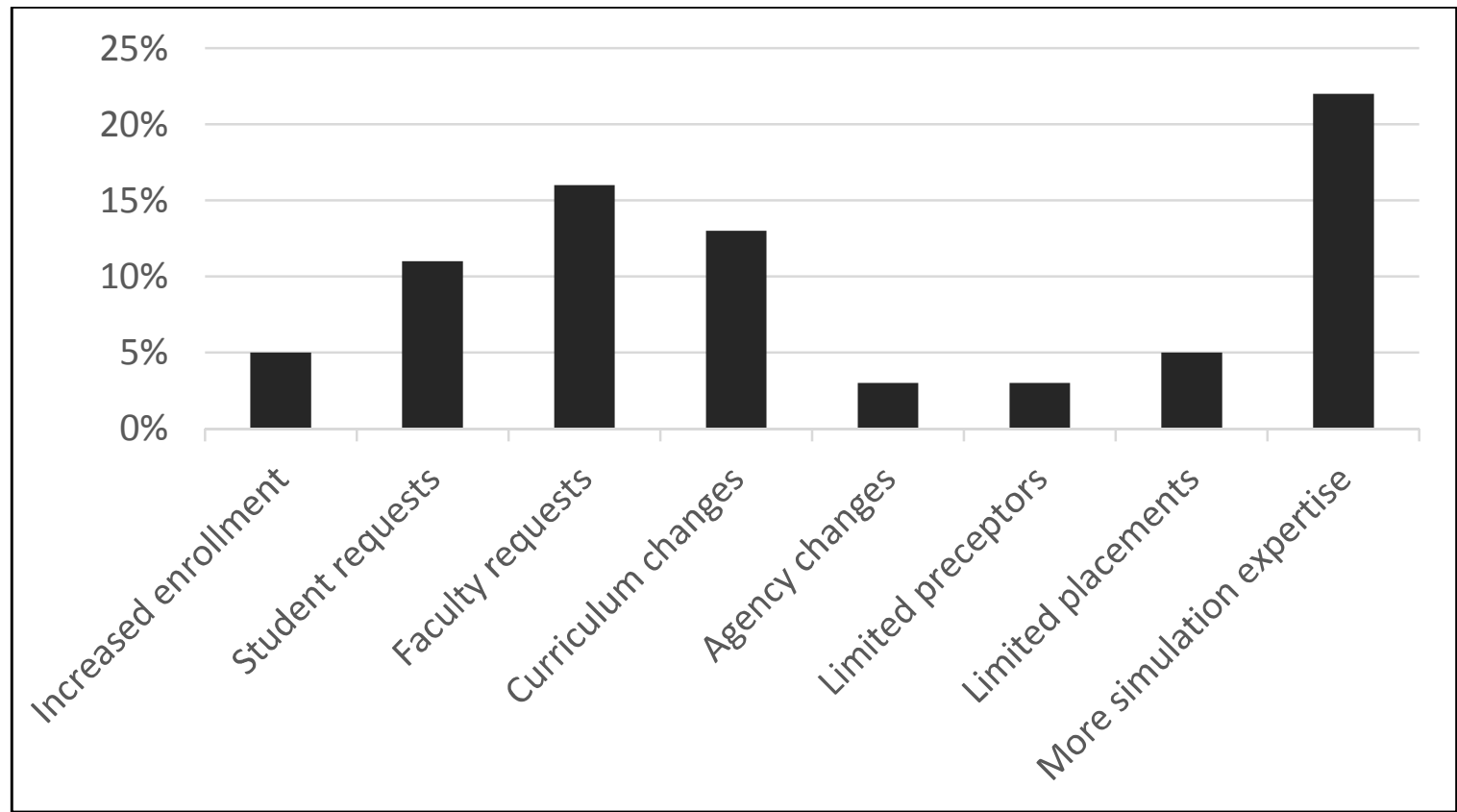

Figure 1. Reasons for Increasing Simulation Hours

During the 2014-2015 academic year, 85\% of responding participants indicated their undergraduate nursing programs programs planned to increase hours of simulation. Reasons for increasing hours of simulation were most strongly prompted by curriculum changes, followed by faculty requests and enhanced simulation expertise. Less influential factors were increased student enrollment and student requests. Limited placement availability, agency changes, and limited preceptor availability were reported as the least influential motivating factors (See figure 2).

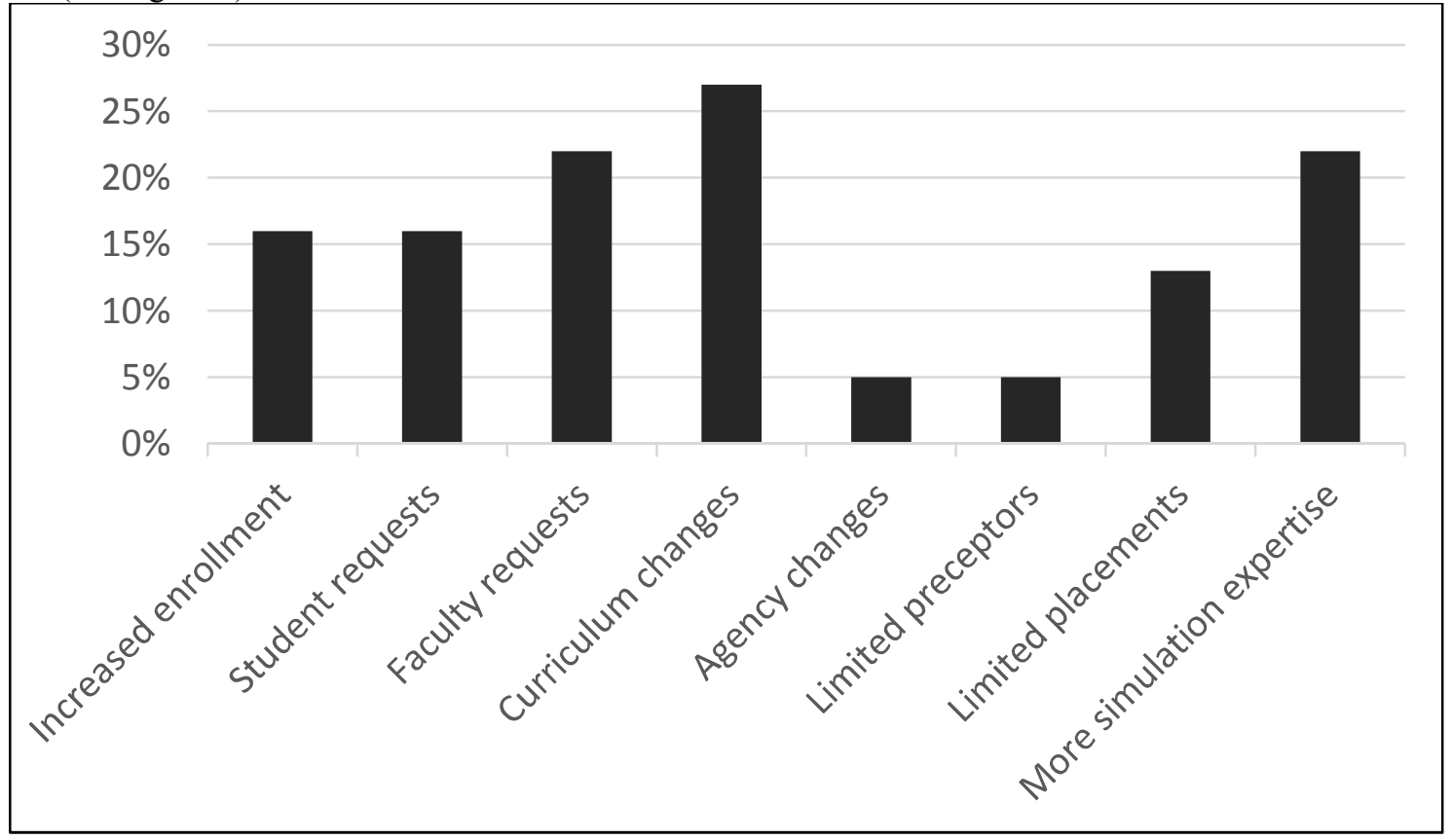

Figure 2. Reasons for Planning to Increase Simulation Hours

Given concerns about dwindling clinical placements and available preceptors in Ontario, an area of inquiry centred upon the use of SBL to replace hours that students typically spend in direct clinical practice. Under half (38\%) of responding participants indicated that their nursing programs routinely utilized simulation for this reason. Of these respondents, $13 \%$ indicated that this purpose of simulation is an established practice in their nursing program curriculum and $13 \%$ indicated simulation was used as an alternative learning experience when clinical placements are unable to accommodate students, for example due to an infectious outbreak on a unit. Amidst current concerns about access to clinical placements, almost no participant (3\%) indicated their program was undertaking pilots to replace direct clinical hours with a portion of simulation hours. Within 
programs that routinely use SBL to replace direct clinical hours, there is a wide variation. Overall, an average of $23.5 \%$ of clinical hours was reported as typically replaced with simulation experiences, however, participants indicated that their programs may replace between $3 \%$ to $38 \%$ of clinical hours with simulation (see figure 3 ).

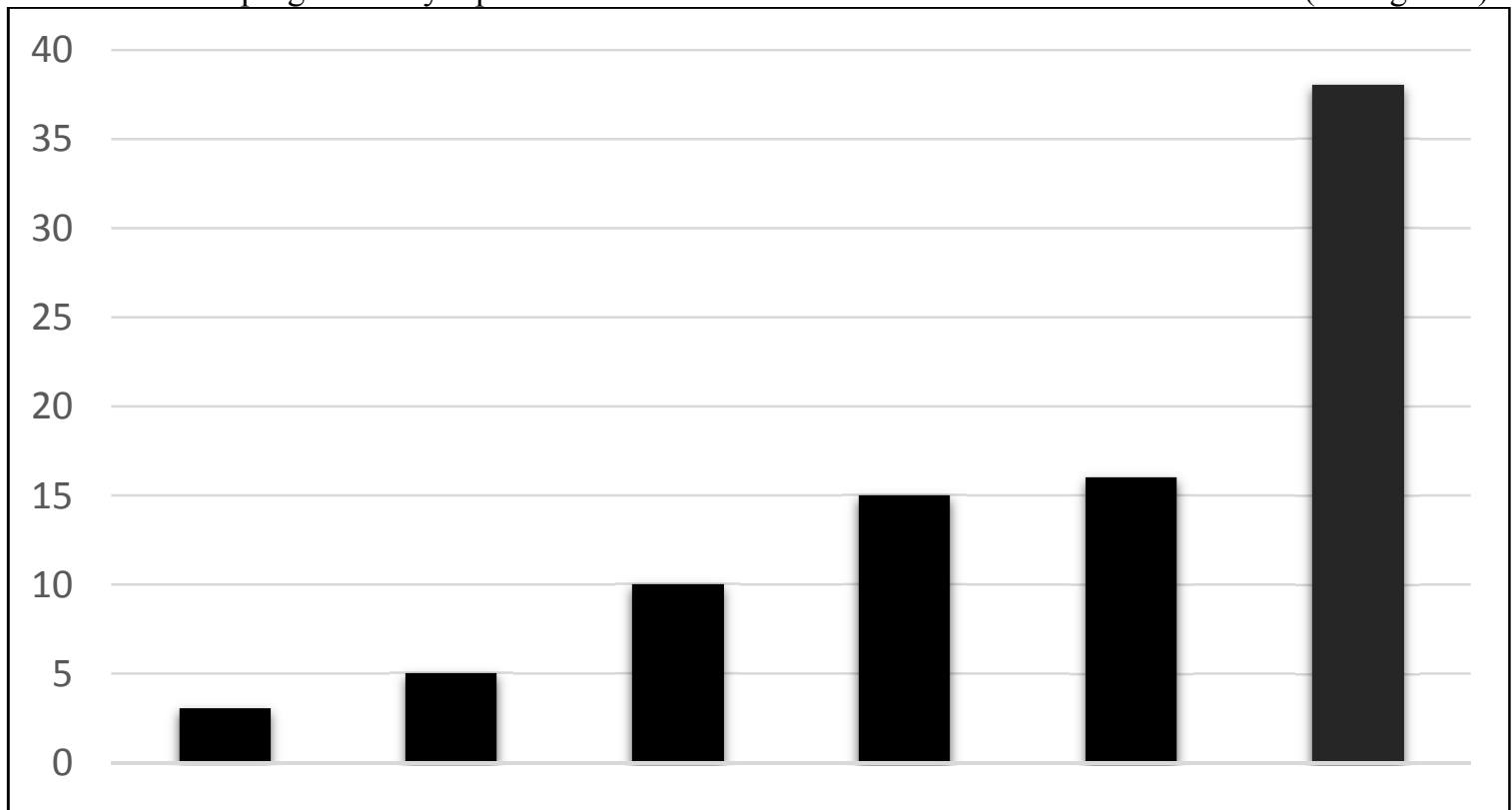

Figure 3. Percentage of Clinical Hours Replaced by Simulation on a Regular Basis

In addition, the hours of simulation to replace eight hours of clinical practice was reported as ranging between 1 hour to 16 hours among nursing programs (see figure 4).

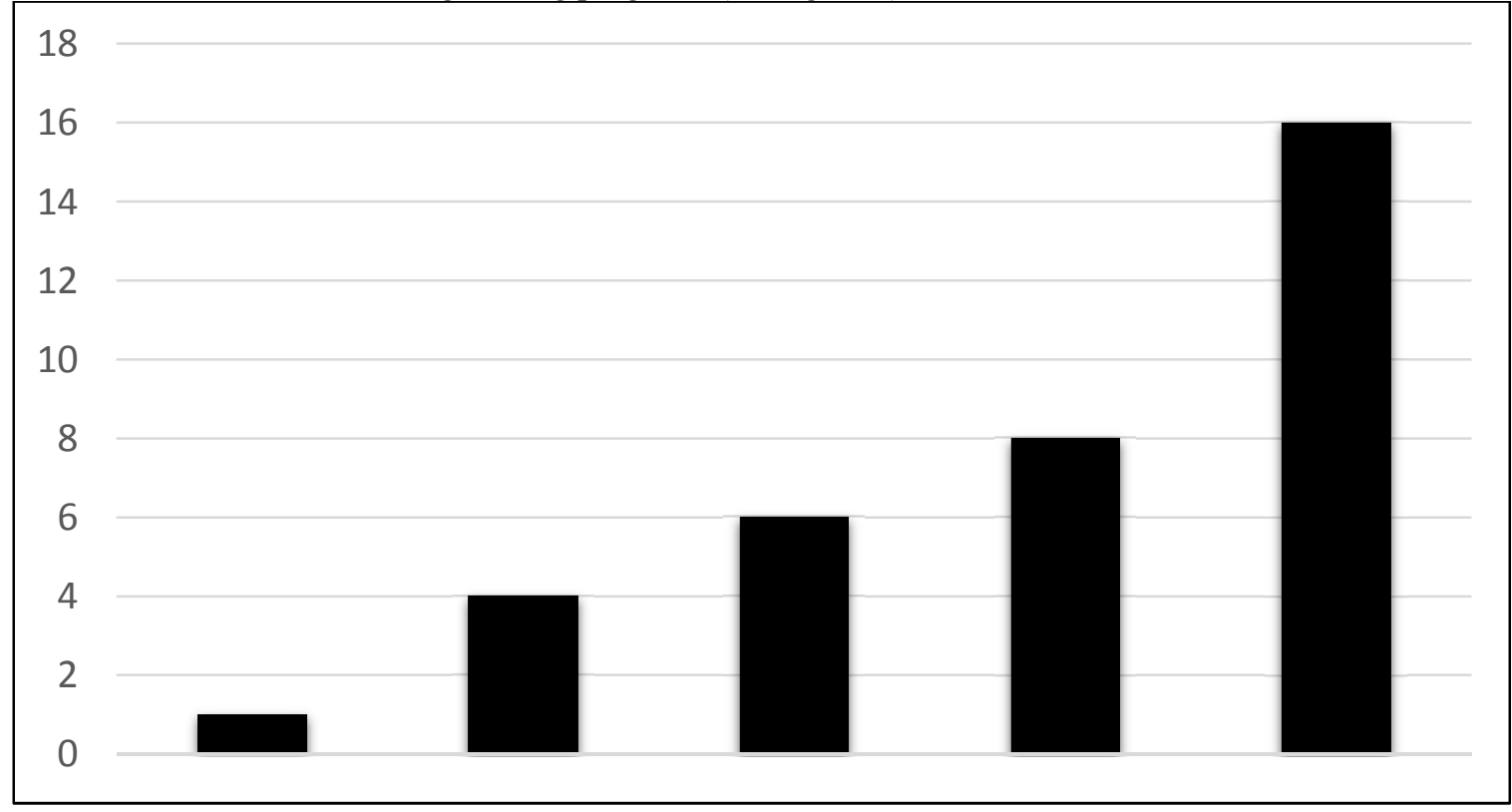

Figure 4. Number of Hours of Simulation Used to Replace Direct Clinical Practice

\subsection{Simulation Foci}

Among undergraduate nursing programs in Ontario, simulation foci was reported by participants to include a wide variety of fields within clinically-based or community-based nursing. However, clinical simulation foci were most frequently employed and included: medical simulations, maternal/child simulations, pediatric simulations, and surgical simulations. Among many nursing programs, community health and mental health simulations were reported as fairly frequently employed, whereas interprofessional simulations and intraprofessional simulations were less often employed. Out-patient simulations, emergency preparedness simulations, disclosure of adverse events simulations, out-patient mental health/psychiatric simulations, and recovery room simulations were reported as infrequently used. Not surprisingly, participants also reported that simulations in their nursing programs most frequently focused on adult and pediatric populations, with older 
adult populations focused on substantially more often than young adults. Populations or groups less frequently focused on included women, adolescents, homeless persons, families, and aboriginal persons.

\subsection{Simulation Evaluation Practices}

Participants were asked to respond to a series of questions about evaluation practices for various components of SBL in their nursing programs. These included: i) the evaluative purpose; ii) the effectiveness of the evaluation; iii) the knowledge and skills of personnel; and iv) student reports of their experiences and perceptions. In regard to participants' overall perceptions of the significance of employing a range of evaluation practices, most responses revealed that both the evaluation of student learning and performance via simulation experiences $(100 \%$ of participants) and the evaluation of the simulation itself ( $96 \%$ of participants) were especially highly valued to ensure high quality simulation experiences.

In regard to the purpose of the evaluation, simulations typically are used to evaluate students' performance and competence according to four purposes (formative, summative, high stakes, and remedial evaluation). Collectively, their purpose is to assess if (and how well) the learner is able to meet the learning outcome, improve current practice, and identify gaps. They also may be used to assign a grade or to score learner performance (Adamson, Jeffries, Rogers, 2012; Bensfield et al., 2012; INACSAL Standards Committee, 2016b). All responding participants $(100 \%)$ felt that formative evaluation approaches were important or very important, most participants $(91 \%)$ felt that remedial evaluation approaches were important or very important, and many participants (81\%) felt that summative evaluation approaches were important or very important. In contrast, only $62 \%$ of respondents reported that high stakes evaluation approaches were very important or important to them, with $38 \%$ considering this purpose of evaluation to be neither important or unimportant or to be unimportant. About student evaluation in simulation, some participants commented: "we are in an early stage of using simulation for summative evaluation", "simulation is the safe place for making mistakes, so should not be used as a high stakes testing environment" and "we mostly use simulation with formative assessment therefore this aspect is most important to us."

Participants were asked to respond with their perceptions of the importance of the use of evaluation practices to ensure the effectiveness and quality of simulations within their nursing programs. Virtually, all responding participants felt that the evaluation of simulation itself to be important or very important, yet only $40 \%$ reported that standardized approaches to evaluation currently were employed in their nursing program. In regard to the use of standardized student evaluation tools in their nursing program, most participants (75\%) reported the consistent employment of a standardized tool for summative evaluation, followed by high stakes evaluation $(62.5 \%)$, formative evaluation $(58.8 \%)$, and finally, remedial evaluation $(45.5 \%)$. Participants' comments suggested challenges are encountered in developing and utilizing consistent, formalized, and standardized processes. Some challenges reported included: a need for better simulation education and faculty development, lack of time, a need for faculty "buy-in", a lack of valid and reliable tools, and a need to develop specific simulation coordinator and education positions. Some participants commented: "this is an area that requires development in our program", "as our program develops, we will be implementing for valid and rigorous processes", "the onus is on us to appropriately evaluate simulation teaching strategies to provide the best experience for students and ultimately contribute to safer patient care", and "very important - however the curriculum is so jammed packed and there is never sufficient time".

Most participants $(90 \%)$ also considered the evaluation of personnel (e.g., faculty, staff, educators, facilitators, etc.) directly involved in simulation utilization to be very important or important. Of responding participants, $50 \%$ noted that their nursing programs required a specific educational or experiential background for personnel. However, the specific background required widely varied among nursing programs, and collectively included simulation-specific credentials, a training certificate by external simulation specialists, a graduate degree with simulation focus, internal training with experts, or train the trainer approaches. In addition, less than half of responding participants $(47 \%)$ indicated that their nursing programs employed standardized approaches to professional development (e.g., orientation, mentorship, structured professional development activities) and only $20 \%$ of participants indicated that their nursing programs employed standardized approaches to the evaluation of personnel (e.g., review of professional portfolios, direct observation, review of student feedback). Two participants commented on this "gap" at their institutions: "many programs are not aware of the educational opportunities for those working in simulation" and "there is not enough knowledge on what is involved in being a competent simulation facilitator/educator". Other barriers reported included: cost of professional development activities, lack of infrastructure support and funding, lack of time, and too few personnel involved in simulation utilization in their program. Interestingly, enhanced faculty expertise was cited as an important impetus for the increased use of simulation among Ontario nursing programs since 2013, and in conjunction, among participants, a recognition of the need for well-qualified, well-developed personnel is apparent. Two participants commented: the "position has grown from lab role and has evolved as the science of simulation has evolved. As the pedagogy is advancing, the roles are also changing" and "the educator role needs 
to broaden to ensuring best practices are incorporated".

Critical to the evaluation of simulation practices and approaches may be incorporation of students' assessments of their learning and outcomes of learning in SBL experiences. In general, responding participants indicated that within their nursing programs, informal student evaluations rather than formal student evaluations were most frequently gathered, and informal evaluations typically occurred when the simulation was conducted. Feedback sought most often in informal evaluations focused on students' perceptions of the overall quality of the simulation rather than the ability of the simulation to facilitate their meeting of learning outcomes or the details of the simulation, such as pre-brief activities, debriefing activities, or evaluative components. In the nursing programs where participants indicated that formal student evaluation occurs, student feedback sought most often focused on the overall quality of the simulation, and also the ability of the simulation to facilitate the meeting of learning outcomes, with feedback regarding the details of the simulation less often invited from students. Participants also responded that formal student evaluation tended to be sought at various points in the term, such as when the simulation is conducted or as a part of the end of term formal course evaluation. Comments by participants indicated a general recognition of the value of, and efforts to, incorporate informal and formal student assessments in simulation curriculum development, yet they also suggested a need for further improvement. Some participants commented: it is "work in progress", "another area we need to develop further", and "great idea to add a simulation design/instructional evaluation".

\section{Discussion and Recommendations}

SBL has become a well utilized strategy in undergraduate Ontario nursing education among college and university programs, and is most often used for formative, remedial, and summative purposes in clinical or labbased nursing courses that incorporate medical and surgical foci. Less commonly used is simulation for high stakes testing, which is interesting in the context of recent discussions in the literature that have emerged that focus on the potential value of testing for multiple purposes, especially when working with upper level students (Bensfield, Olech, \& Horsley, 2012; Rizzolo, Kardong-Edgren, Oermann, \& Jeffries, 2015). However, there is remains a gap in the literature regarding current practices on the use and evaluation of high stakes testing in undergraduate nursing education (Boulet, 2008; Gantt, 2013; Kardong-Edgren, Hanberg, Keenan, Ackerman, \& Chambers, 2011; Sullivan, 2014). Participants' responses in this study also reiterated a perception that simulation use for high stakes testing was not considered an overly valuable evaluation tool compared to the more common current uses of simulation for evaluation.

A variety of evaluation practices applied to examining the simulation itself (e.g., theoretical constructs, linkages to learning outcomes, evaluative tools such as rubrics and checklists, pre-briefing methods, and debriefing methods; evaluation of personnel directly involved in teaching-learning activities) are critical quality improvement initiatives (Adamson et al., 2012; INACSL, 2013; Decker, Utterback, Thomas, Mitchell, \& Sportsman, 2011; Willhaus, Burleson, \& Palaganas, \& Jeffries, 2014). Study participants deemed the evaluation of the effectiveness of simulations as vital, yet less than half of the programs currently undertake standardized approaches to evaluation. This disconnect, likely reflective of the still relative newness of SBL as a pedagogical approach in nursing educational programs, is a critical gap that must be addressed in order to ensure rigour in evaluations and promote high quality learning experiences. In addition, the majority of participants considered evaluation of personnel involved in delivering simulation as crucial to high quality simulation, yet reported that less than half of programs engaged in structured professional development opportunities or standardized evaluation practices regarding personnel. Once again, it must be noted that recognizing the value of evaluation components (in this case evaluation of personnel) is both essential and demonstrated, but following through with consistent, evidence-based approaches for enacting this evaluation is a critical next step. While noting the significance of quality improvement initiatives, participants also noted a number of challenges and barriers including those related so costs, lack of time, lack of support, and lack of available resources or tools as hindrances to ensuring consistent and tested high quality simulation experiences for students. As a community of educators, developing, evaluating, and disseminating evidence-based mechanisms by which these types of evaluations may take place is an important next step in the evolution of simulation pedagogy.

Literature indicates that there is a strong trend to increase SBL experiences for students in order to prepare them with the competence and confidence required to practice in complex healthcare environments and to enhance patient safety (Norman, 2012; Rickets, 2011; Topping et al., 2015). The study results demonstrate that this trend has been taking place in Ontario nursing programs since at least 2013. In Canada, a heightened concern about decreasing clinical placement opportunities and competition for both placements and preceptors in conjunction with increased student enrolment and faculty shortages (Canadian Association of Schools of Nursing, 2007) has driven debates about increasing simulation hours to replace direct clinical practice in order to ready students for clinical practice. Interestingly, these concerns were reported by participants as less influential, with curriculum changes, faculty requests, and enhanced simulation expertise propelling increased simulation utilization in Ontario undergraduate nursing programs over the past two years. Furthermore, there is a lack of 
standardization in regard to the use of simulation to replace direct clinical practice in Ontario undergraduate nursing education. This is particularly important to attend to given growing concerns regarding the scarcity of clinical placements and preceptors commonly experienced across Canada (Canadian Association of Schools of Nursing, 2007; Smith et al., 2007). However, as we continue to develop and evaluate simulation pedagogy, we must consider our motivation behind these teaching-learning advances and how it is being communicated. The typical argument that SBL may be used to "shore up" the clinical portion of a nursing program when there are challenges finding placements was indeed reflected in the study data. However, more strongly expressed was a desire by nursing educators to implement and expand the use of simulation because of its inherent strength as a teaching-learning-evaluation tool. Simulation pedagogy is simply put, good pedagogy. Ensuring that it is developed, implemented, and evaluated well is not a unique requirement related to this approach, but rather the very basic requirement of all pedagogical approaches. Within the context of recent evidence (Alexander, et al. 2015; Hayden et al., 2014) that up to 50 percent of clinical hours can be safely substituted by high-quality simulation experiences to produce comparable end-of-program educational outcomes and ready-to-practice graduates, ensuring that robust and evidence-based evaluation measures from multiple perspectives are included is critical.

Overall, a strong indication that SBL is viewed by the participants as an essential educational component because it can effectively prepare students with the required prerequisite knowledge, skills, and abilities to meet entry to practice competencies and ultimately promote job readiness of new registered nurses is apparent. Furthermore, Ontario nursing programs are increasingly using SBL experiences to these ends, with overall trends of increased SBL and development of simulation expertise. Yet, as a whole, the findings suggest a perception among many participants that simulation practices and approaches, although rapidly developing, still remain in early stages of growth and development.

Based on study results, recommendations for the ongoing evolution of the science of simulation in Ontario undergraduate nursing education can be established, and a few important ones are highlighted.

1. As SBL becomes more integrated into undergraduate nursing education, expanding evidence supporting the use of simulation-based learning as valuable teaching-learning-evaluation strategies is a high priority. Further research about the effectiveness on various areas of student performance (i.e. confidence, competency, safety, knowledge, domains of learning, etc.) with an emphasis on rigor and quality of evidence pertaining to the use of best practices to support optimal learning and outcomes is critically needed.

2. The establishment of evidence that supports the appropriate and consistent use of SBL as a replacement for clinical hours (e.g. the number of hours of simulation used to replace hours of direct clinical practice).

3. Further development of the utilization of a variety of simulation modalities (summative, formative, high stakes, and remedial) for evaluative purposes of student learning and performance, and in particular high stakes evaluation which remains underutilized and challenging to implement well (Willhaus, Burleson, Palaganas, \& Jeffries, 2014).

4. Further development and implementation of rigorous evaluation practices pertaining to both student performance and simulation pedagogy itself, including investing in current efforts to develop and utilize best practice guidelines in simulation (INACSL Standards Committee, 2016a).

5. Increased support and resources to support simulation utilization and simulation methodology in nursing education, especially in regard to professional credentialing and training and ongoing professional development of simulation educators (Deutsch \& Palaganas, 2015; Nicholas, Spain, Lopez, \& Walker, 2015).

6. Replacement of "simulation" as a stand-alone term with "simulation pedagogy" or "simulation-based learning (SBL)" where the intent is to demonstrate how this approach is used through the development, implementation, and evaluation of quality teaching-learning methods unique to this modality.

7. Be judicious in justifying the use of simulation pedagogy or SBL. While one important use for this approach may be to augment direct clinical experiences, the evidence for much broader application of simulation experiences for learners in nursing programs is no longer emerging- it is well established. Simulation pedagogy is good pedagogy and framing it as a secondary source for a learning experience not only positions it as a second choice, but frames it in a limiting way.

\section{Conclusion}

The study findings provide important insights into simulation utilization and simulation evaluation practices and approaches currently employed in undergraduate nursing education in Ontario, Canada. As such, they contribute to ongoing discussions about current trends and challenges experienced among institutions in the use of simulation. To date, while literature exists on some of the common practices and approaches to SBL in education, standardization has not resulted (Leighton, 2013). There also has been little available data broadly, and no available data in Ontario, describing simulation utilization and simulation evaluation in nursing education. Ultimately, developing an accurate understanding of the common range and patterns of utilization of simulation 
for nursing education and the practices and approaches to evaluation of simulation is a critical starting point in the comprehensive development of strategies geared toward effective integration of simulation into undergraduate nursing curricula.

\section{References}

Adamson, K. A., Kardong-Edgren, S., \& Willhaus, J. (2013). An updated review of published simulation evaluation instruments. Clinical Simulation in Nursing, 9(9), e393-e400. http://dx.doi.org/ 10.1016/j.ecns.2012.09.004

Adamson, K. Jeffries, P. \& Rogers, K. (2012). Evaluation: A critical step in simulation practice and research. In P. Jeffries (Ed.), From Conceptualization to Evaluation (2nd ed.), pp. 131-161. New York, NY: National League for Nursing.

Aebersold, M., \& Tschannen, D. (2013). Simulation in nursing practice: The impact on patient care. OJIN: The Online Journal of Issues in Nursing, 18 (2). DOI: 10.3912/OJIN.Vol18No02Man06

Akhtar-Danesh, N., Baxter, P., Valaitis, R. K., Stanyon, W., \& Sproul, S. (2009). Nurse faculty perceptions of simulation use in nursing education. Western Journal of Nursing Research, 31 (3), 312-329. DOI: $10.1177 / 0193945908328264$

Alexander, M. Durham, C. F., Hooper, J. I., Jeffries, P. R., Goldman, N., Kardong-Edgren, S., Kesten, K. S., Spector, N., Tagliareni, E., Radtke, B., \& Tillman, C. (2015). NCSBN simulation guidelines for prelicensure nursing programs. Journal of Nursing Regulation, 6(3), 39-42. http://dx.doi.org/10.1016/S2155-8256(15)30783-3

Andreatta, P. \& Lori, J. (2014). Developing clinical competence and confidence. In B. Ulrich \& B. Mancini (Ed.), Mastering simulation: A handbook for success (pp.28-47). Indianapolis, IN: Sigma Theta Tau International.

Bensfield, L., Olech, M., \& Horsley, T. (2012). Simulation for high-stakes evaluation in nursing. Nurse Educator, 37 (2), 71-74. DOI: 10.1097/NNE.0b013e3182461b8c

Boulet, J. R. (2008). Summative assessment in medicine: the promise of simulation for high-stakes evaluation. Acad Emerg Med, 15(11), 1017-1024. DOI: 10.1111/j.1553-2712.2008.00228.x

Canadian Association of Schools of Nursing (CASN). (2015). Practice domain for baccalaureate nursing education: Guidelines for clinical placements and simulation. Ottawa, ON: Author. Retrieved from http:/www.casn.ca/wp-content/uploads/2015/11/Draft-clinical-sim-2015.pdf

Canadian Association of Schools of Nursing (CASN) (2007). CASN/ACESI Clinical placement projects, Project 3: Inventory of the use of simulated clinical learning experiences and evaluation of their effectiveness. Ottawa, ON: Author. from http://www.cihc.ca/files/complementary/CASN\%20Inventory\%20of\%20Simulation.pdf

Cant, R. P., \& Cooper, S. J. (2010). Simulation-based learning in nurse education: systematic review. Journal of Advanced Nursing, 66 (1), 3-15. DOI: 10.1111/j.1365-2648.2009.05240.x

Decker, S., Utterback, V. A., Thomas, M. B., Mitchell, M., \& Sportsman S. (2011). Assessing continued competency through simulation: A call for stringent action. Nursing Education Perspectives, 32 (2), 120-125. Retrieved from http://www.nln. org/nlnjournal/index.htm

Deutsch, E. \& Palaganas, J. (2015). SSH accreditation standards. In J. Palaganas, J. Maxworthy, C. Epps, \& M. Mancini, Defining excellence in simulation programs (pp. 2-16). Philadelphia, PA: Wolters Kluwer.

Gantt, L. (2013). The effect of preparation on anxiety and performance in summative simulations. Clinical Simulation in Nursing, 9(1), e25-33. http//dx.org/10.1016/j.ecns.2011.07.004

Hayden, J., Smiley, R., Alexander, M., Kardong-Edgren, S., \& Jeffries, P. (2014). The NCSB National Simulation Study: A longitudinal, randomized, controlled study replacing clinical hours with simulation in prelicensure nursing education. Journal of Nursing Regulation, 5(2), S43-S64. Retrieved from https://www.ncsbn.org/JNR_Simulation_Supplement.pdf

International Nurse Association of Clinical Simulation in Learning (INACSL) Standards Committee (2016a). INACSL standards of best practice: Simulation ${ }^{\mathrm{SM}}$ simulation design, Clinical Simulation in Nursing, 12(S), S5-S26. DOI: http://dx.doi.org/10.1016/j.ecns.2016.09.005

International Nurse Association of Clinical Simulation in Learning (INACSL) Standards Committee (2016b). INACSL standards of best practice: Simulation ${ }^{\mathrm{SM}}$ participant evaluation. Clinical Simulation in Nursing, 12(S), S26-S29. http://dx.doi.org/10.1016/ j.ecns.2016.09.009

Kardong-Edgren, S., Hanberg, A. D., Keenan, C., Ackerman, A., \& Chambers, K. C. (2011). A discussion of high-stakes testing: An extension of a 2009 INACSL conference roundtable. Clinical Simulation in Nursing, 7(1), e19-e24. DOI:10.1016/j.ecns.2010.02.002

Leighton, K. (2013). Simulation in nursing. In A. Levine (Ed.). The comprehensive textbook of healthcare simulation. (pp. 425-436). New York, NY: Springer Science \& Business Media. DOI:10.1007/978-14614-5993-4 29 
Nicholas, C., Spain, A., Lopez, C., Walker, K. (2015). Development of SSH certified healthcare simulation educator program: Design of a valid, defensible, and cost effective program. In J. Palaganas, J. Maxworthy, C. Epps, \& M. Mancini, Defining excellence in simulation programs (pp. 39-48). Philadelphia, PA: Wolters Kluwer.

Norman, J. (2012). Systematic review of the literature on simulation in education. ABNF Journal, 23 (2), 24-28. Retrived from https://www.ncbi.nlm.nih.gov/pubmed/22774355

Ricketts, B. (2011). The role of simulation for learning within pre-registration nursing education: A literature review. Nurse Education Today, 31, 650-654. DOI:10.1016/j.nedt.2010.10.029

Rizzolo, M., Kardong-Edgren, S., Oermann, M., \& Jeffries, P. (2015). The National League for Nursing project to explore the use of simulation for high-stakes assessment: Process, outcomes, and recommendations. Nursing Education Perspectives, 36(6), 299-303. DOI:10.5480/15-1639

Shin, S., Park, J. H., \& Kim, J. H. (2015). Effectiveness of patient simulation in nursing education: Metaanalysis 35(1), 176-182. DOI: http://dx.doi.org/10.1016/j.nedt.2014.09.009

Smith, P. M., Spadoni, M., Seeley, J., Sevean, P., Dampier, S. \& Strickland, S. (2007). Project 1: An inventory of strategies to deliver nursing and interprofessional clinical placements in Canada. Ottawa, ON: Canadian Association of Schools of Nursing/L'Association Canadienne des écoles de sciences infirmières. Retrieved from: http://www.twu.ca/sites/default/files/icp-report.pdf

Sullivan, D. (2014). A concept analysis of "high stakes testing". Nurse Educator, 39(2), 72-76. Retrieved from DOI: 10.1097/NNE.0000000000000021

Todd, M., Manz, J. A., Hawkins, K. S., Parsons, M.E. \& Hercinger, M. (2008). The development of a quantitative evaluation tool for simulations in nursing education. International Journal of Nursing Scholarship, 5 (1), 1-17. DOI: 10.2202/1548-923X.1705

Topping, A., Bøje, R. B., Rekola, L., Hartvigsen, T., Prescott, S., Bland, A., \& Hannula, L. (2015). Towards identifying nurse educator competencies required for simulation-based learning: A systemised rapid review and synthesis. Nurse Education Today, 35(11), 1108-1113. http://doi.org/10.1016/j.nedt.2015.06.003

Willhaus, J., Burleson, G., Palaganas, J., \& Jeffries, P. (2014). Authoring simulations for high-stakes student evaluation. Clinical Simulation in Nursing, 10(4), e177-e182. http://dx.DOI.org/10.1016/j.ecns.2013.11.006 